\title{
MULTIVARIATE MOMENT TYPE OPERATORS: APPROXIMATION PROPERTIES IN ORLICZ SPACES
}

\author{
CARLO BARDARO AND ILARIA MANTELLINI
}

Abstract. In this paper modular convergence theorems in Orlicz spaces for multivariate extensions of the one-dimensional moment operator are given and the order of modular convergence in modular Lipschitz classes is studied.

Mathematics subject classification (2000): 41A35, 47G10, 46E30. theorem

Key words and phrases: Orlicz spaces, weighted metric type kernels, moment operators, Korovkin

\section{REFERENCES}

[1] F. Altomare AND M. CAMPITI, Korovkin-type approximation theory and its applications, Walter de Gruyter, Berlin, New York, 1994.

[2] F. BARBIERI, Approssimazione mediante nuclei momento, Atti Sem. Mat. Fis. Univ. Modena, 32, (1983), $308-328$

[3] C. BARDARO AND I. MANTELLINI, Linear integral operators with homogeneous kernel: approximation properties in modular spaces. Applications to Mellin-type convolution operators and to some classes of fractional operators, Applied Mathematics Reviews, vol I, World Scientific Publ., River Edge, NJ, Edited by G. Anastassiou, (2000), 45-67.

[4] C. Bardaro And I. Mantellini, Korovkin theorem in modular spaces, Comment. Math. Prace Mat., 47(2), (2007), 239-253.

[5] C. BARDARO AND I. MANTELLINI, Korovkin theorem in multivariate modular function spaces, to appear (2008).

[6] C. BARdaro, J. MusielaK AND G. VinTi, Nonlinear integral operators and applications, De Gruyter Series in Nonlinear Analysis and Appl., Vol. 9, 2003.

[7] C. BARDARO AND G. VINTI, Modular convergence in generalized Orlicz spaces for moment type operators, Appl. Anal., 32, (1989), 265-276.

[8] P. L. ButZER AND R. J. Nessel, Fourier Analysis and Approximation I, Academic Press, New York-London, 1971.

[9] F. Degani Cattelani, Nuclei di tipo “distanza” che attutiscono i salti in una o piú variabili, Atti Sem. Mat. Fis. Univ. Modena, 30, (1981), 299-321.

[10] R. A. DEVORE, The approximation of continuous functions by positive linear operators, Lecture notes in Math., 293, Springer-Verlag, 1972.

[11] C. FIOCCHI, Two-dimensional moment kernels and convergence in area, Atti Sem. Mat. Fis. Univ. Modena, 33(2), (1986), 291-311.

[12] C. FIOCCHI, Variazione di ordine $\alpha$ e dimensione di Hausdorff degli insiemi di Cantor, Atti Sem. Mat. Fis. Univ. Modena, 34(2), (1991), 649-667.

[13] P. P. Korovkin, Linear operators and approximation theory, Hindustan, Delhi, 1960.

[14] I. Mantellini, Generalized sampling operators in modular spaces, Comment. Math., Prace Mat. 38, (1998), 77-92.

[15] J. MusielaK, Orlicz. Spaces and Modular Spaces, Springer-Verlag, Lecture Notes in Math., 1034 (1983).

[16] E. D. Rainville, Special Functions, McMillan Co., New York, (1960). 
[17] C. VINTI, Sull'approssimazione in perimetro e area, Atti Sem. Mat. Fis. Univ. Modena, 13, (1964), $187-197$.

[18] V. ZANELLI, Funzioni momento convergenti dal basso in variazione di ordine non intero, Atti Sem. Mat. Fis. Univ. Modena, 30, (1981), 355-369. 